\title{
Technical Note: Design of rockfall net fences and the new ETAG 027 European guideline
}

\author{
D. Peila and C. Ronco \\ Department of Land, Environment and Geo-technology, Politecnico di Torino, Turin, Italy
}

Received: 30 April 2009 - Revised: 24 July 2009 - Accepted: 27 July 2009 - Published: 29 July 2009

\begin{abstract}
The need for protection against rockfall has led to the development of different types of technological solutions that are able to both prevent blocks from detaching from rock walls and to control, intercept or deviate the blocks during movement. Of the many devices that are able to intercept and stop a block, one of the most frequently used is net fence. Many different types of full-scale tests have been carried out, with different test site geometries and procedures to study their behaviour and to certify these devices. This has led to a series of data and information that are not easy to compare. The recent endorsement, by the European Organization for Technical Approvals (EOTA), of a European Technical Approval Guideline (ETAG), which defines how to test and assess the performance of a net fence, is therefore a great innovation that will change both the market and the design procedures of these devices. The most important innovations introduced by this new guideline are here presented and discussed and a net fence design procedure for protection against rockfall is provided.
\end{abstract}

\section{Introduction}

Many mountain side roads and railways are often at risk to rockfall and inhabited areas are often involved (Bunce et al., 1997; Guzzetti et al., 2003; Jaboyedoff et al., 2005; Locatelli, 2005; Peila and Guardini, 2008). Rockfall can be described as the quick bouncing, rolling and sliding movement of one (or several) boulders down a slope which can reach significant kinetic energy as it (they) travels. The speed val-

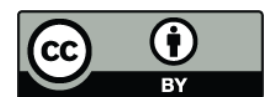

Correspondence to: D. Peila (daniele.peila@polito.it) ues range from a few metres per second to up to $25 \div 30 \mathrm{~m} / \mathrm{s}$ (Broili, 1973; Giani, 1992).

The need for protection against this phenomenon has led to the development and use of different types of technological solutions. These solutions can either prevent the blocks from breaking off the rock walls, thus reducing the frequency of the collapses, or control, intercept or deviate the blocks during their movement. These latter devices include ditches, rockfall shelters, ground embankments and net fences made of metallic meshes (Peckover and Kerr, 1977; Peila et al., 2007).

Analytical procedures for the mathematical description of rockfall phenomena have been established by several researchers and these procedures have led to the development of various types of statistical forecasting procedures (Descoudres and Zimmermann, 1987; Giani, 1992; Azzoni et al., 1995; Agliardi and Crosta, 2003; Yang et al., 2004). When the best position with reference to the interception percentage of the trajectories, the corresponding maximum bouncing height and the kinetic energy have been established, a suitable device can be chosen. In the past, many tests were carried out by manufacturers and universities to define the maximum energy that can be safely absorbed by net fences (Smith and Duffy, 1990; Duffy and Wade, 1996; Gerber, 1999; Grassl et al., 2003; Peila et al., 2006), but these tests were developed using different standards and procedures and the results were not easily comparable. For this reason, the European Organization for Technical Approvals (EOTA) (http://www.eota.eu) has endorsed a new European Technical Approval Guideline "Falling rock protection kits" (ETAG 027), where a testing procedure for CE marking of a net fence (which has been called falling rock protection kit in the guideline) has been defined.

EOTA was founded after the drawing up of Construction Products Directive 89/106/EEC (CPD) and it has the goal

Published by Copernicus Publications on behalf of the European Geosciences Union. 

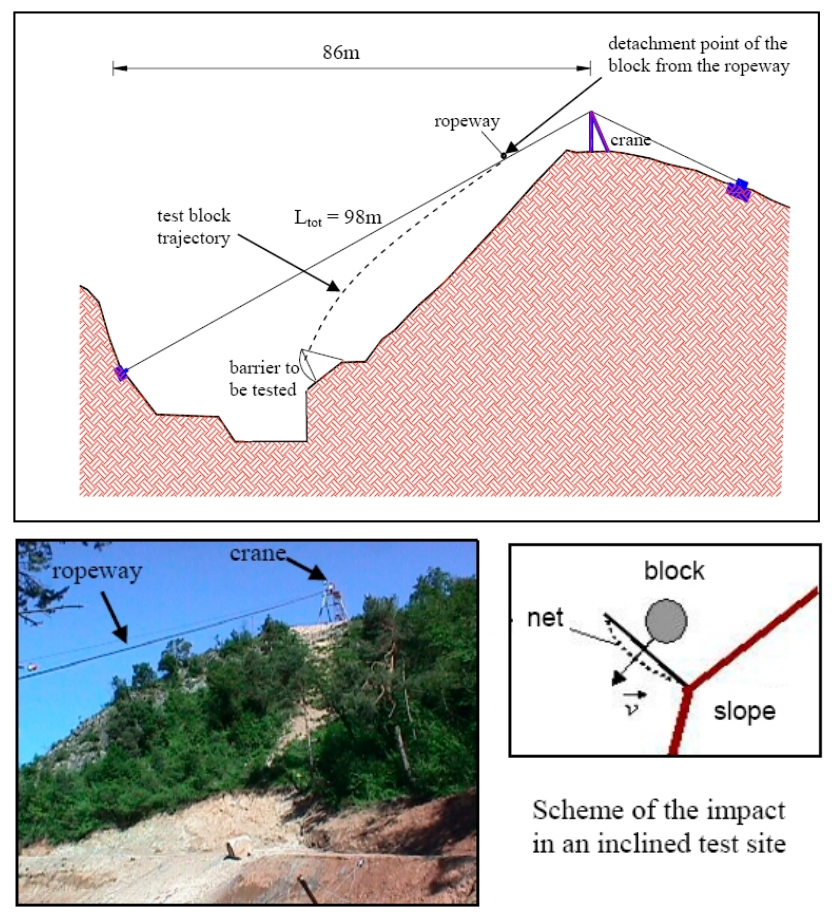

Scheme of the impact in an inclined test site

Fig. 1. Example of the inclined test site in Meano (TN), Italy (Peila et al., 2006).

of removing technical obstacles, in the manufacturing sector, for the European falling rock protection kit market through:

- the compliance of trade marks with six essential requirements: (1) mechanical resistance and stability; (2) safety in the case of fire; (3) hygiene, health and environment; (4) safety in use; (5) protection against noise; (6) energy economy and heat retention, which globally define the suitability of use of a product;

- the transformation of these six requirements to product requirements;

- the determination of the performances of products used in net fence construction by means of technical specifications;

- the attestation of conformity of the products;

- CE marking of the products.

In order to establish whether a product is "fit for its intended use", it must comply with a European harmonized standard or European Technical Approval (ETA), if no corresponding standard exists. According to the Construction Products Directive, an ETA document sets the basis for the certification procedure, which must be carried out by an Approved Body that has been recognized by the European Commission (Nando - New Approach Notified and Designated Organization - Information System, http://ec.europa.eu/enterprise/ newapproach/nando). Since no relevant European harmonized standard existed for rockfall net fences, the European Commission gave a mandate to EOTA members to develop a guideline (ETAG) in order to:

- identify the relevant and regulatory characteristics of the net fences;

- establish a method for the verification and assessment of these characteristics;

- identify the threshold values that have to be respected for technical reasons;

- define the relevant identification tests for the kit components.

The guideline was therefore drawn up by a working group, which consisted of members nominated by EOTA, who took into account that, when the work was started, no guidelines or standards were available in the EU concerning net fences and only a Swiss guideline had been issued (Gerber, 2001; Guideline for the approval of rockfall protection kits Amendment 2006). The working group also considered that in Italy, France and Austria tenders are usually based on the maximum energy that a net fence can sustain, which is measured using full-scale tests carried out on a prototype, at both inclined and vertical test sites (Figs. 1 and 2). Furthermore, some dynamic numerical calculations had been developed to study the global behaviour of net fences (Nicot et al., 2001; Cazzani et al., 2002; Grassl et al., 2002; Volkwein, 2005; Valfrè, 2006).

\section{Product characterization using full-scale tests}

Net fences consist of a sequence of functional modules made up of an interception structure, a support structure and connection components. They are linked to the foundations which in turn are anchored in the ground. The foundations are not subject to ETA document and are therefore on the discretion of the designer (Table 1). As suggested by the guideline, the certified kit has a minimum of three functional modules (Fig. 3). The energy that can safely be absorbed by a kit during block impact is one of the key points. ETAG 027 defines two energy levels as reference values: SEL "Service Energy Level" and MEL "Maximum Energy Level". SEL is defined as $1 / 3$ of MEL and the kit should be able to retain such a SEL event twice. These energy levels are used to classify the kits (Tables 2 and 3). The tests involve the launching of a plain or reinforced polyhedral concrete block against the central module of the tested kit (Fig. 4). The maximum size of the block must be at least three times smaller than the nominal height of the kit and, in the last metre of the trajectory before the impact, the block must move with an average speed that is greater or equal to $25 \mathrm{~m} / \mathrm{s}$ (Fig. 5). 
Table 1. Net fences main components.

\begin{tabular}{|c|c|c|}
\hline Main parts & Components & Function \\
\hline $\begin{array}{l}\text { Interception } \\
\text { structure }\end{array}$ & $\begin{array}{l}\text { Principal net: made up of metallic cables, wires and/or } \\
\text { bars of different types and materials (for example cable nets } \\
\text { joined by clamps, submarine nets and ring nets. In the last } \\
\text { two cases the rings forming the net are connected to each } \\
\text { other). Additional layers: usually with a finer meshwork } \\
\text { than the principal net made up of cables and/or wires or } \\
\text { other materials. }\end{array}$ & $\begin{array}{l}\text { To bear the direct impact of the mass, deform elastically } \\
\text { and/or plastically and transmit the stresses to the connection } \\
\text { components, the support structure and the foundations. }\end{array}$ \\
\hline $\begin{array}{l}\text { Support } \\
\text { structure }\end{array}$ & $\begin{array}{l}\text { Posts made of different materials, geometries and lengths } \\
\text { (for example, pipes, structural metallic elements) having a } \\
\text { hinge at the bottom. }\end{array}$ & $\begin{array}{l}\text { To keep the erected interception structure. It can be directly } \\
\text { connected to the interception structure or through the con- } \\
\text { nection components. }\end{array}$ \\
\hline $\begin{array}{l}\text { Connection } \\
\text { components }\end{array}$ & $\begin{array}{l}\text { Connecting ropes, steel cables, wires and/or bars of different } \\
\text { types and materials, junctions, clamps, energy dissipating } \\
\text { devices (elements which are able to dissipate energy and/or } \\
\text { allow a controlled displacement when stressed). }\end{array}$ & $\begin{array}{l}\text { To transmit the stresses to the foundation structure during } \\
\text { impact and/or keep the interception structure in position. }\end{array}$ \\
\hline Foundations & $\begin{array}{l}\text { Cables or bars anchored in the ground with adequate grout } \\
\text { (not part of the ETAG). }\end{array}$ & $\begin{array}{l}\text { To transmit the forces derived from the block impact to the } \\
\text { ground. }\end{array}$ \\
\hline
\end{tabular}

Table 2. Falling rock protection kit classes (as used in ETAG 027).

\begin{tabular}{llllllllll}
\hline Energy level classification & 0 & 1 & 2 & 3 & 4 & 5 & 6 & 7 & 8 \\
\hline SEL $[\mathrm{kJ}]$ & - & 85 & 170 & 330 & 500 & 660 & 1000 & 1500 & $>1500$ \\
MEL $[\mathrm{kJ}] \geq$ & 100 & 250 & 500 & 1000 & 1500 & 2000 & 3000 & 4500 & $>4500$ \\
\hline
\end{tabular}

SEL is defined as the kinetic energy of a block that impacts the kit twice and which allows the following constraints to be fulfilled:

- the kit should stop the block during two impacts with the same kinetic energy without maintenance after the first impact. The first block must be removed before the second impact;

- the block should not touch the ground until the kit reaches maximum elongation during both the first and the second impacts; this is necessary to avoid uncontrolled energy dissipation due to ground-block contact and to reduce the energy level absorbed by the barrier;

- after the first impact, there should be no ruptures in the connection components and the mesh openings should be smaller than twice the initial size of the mesh itself; the residual height of the kit (that is, the minimum distance between the lower rope and the upper one measured orthogonally to the reference slope without removing the impacted block) should be higher or equal to $70 \%$ of the kit height (Fig. 6).

The residual height value was chosen as it was considered a reasonable height for an impacted net fence that would permit an already impacted modulus to intercept a new falling
Table 3. Falling rock protection kit categories derived by evaluation of MEL residual height (as used in ETAG 027).

\begin{tabular}{ll}
\hline Category & Residual height \\
\hline A & $\geq 50 \%$ nominal height \\
B & $30<$ nominal height $<50 \%$ \\
C & $\leq 30 \%$ nominal height \\
\hline
\end{tabular}

block. This value is also high enough to prevent the modules next to the impacted one from being slightly perturbed as a consequence of the impact.

MEL is defined as the kinetic energy of an impacting block that fulfills the following constraints:

- MEL>three times SEL;

- the barrier stops the block during the impact;

- the block does not touch the ground until the kit reaches the maximum elongation (Fig. 7).

A SEL value, assumed equal to $1 / 3$ of the MEL value, was adopted to give information about the threshold energy level that does not require any practical repairs after the impact. 

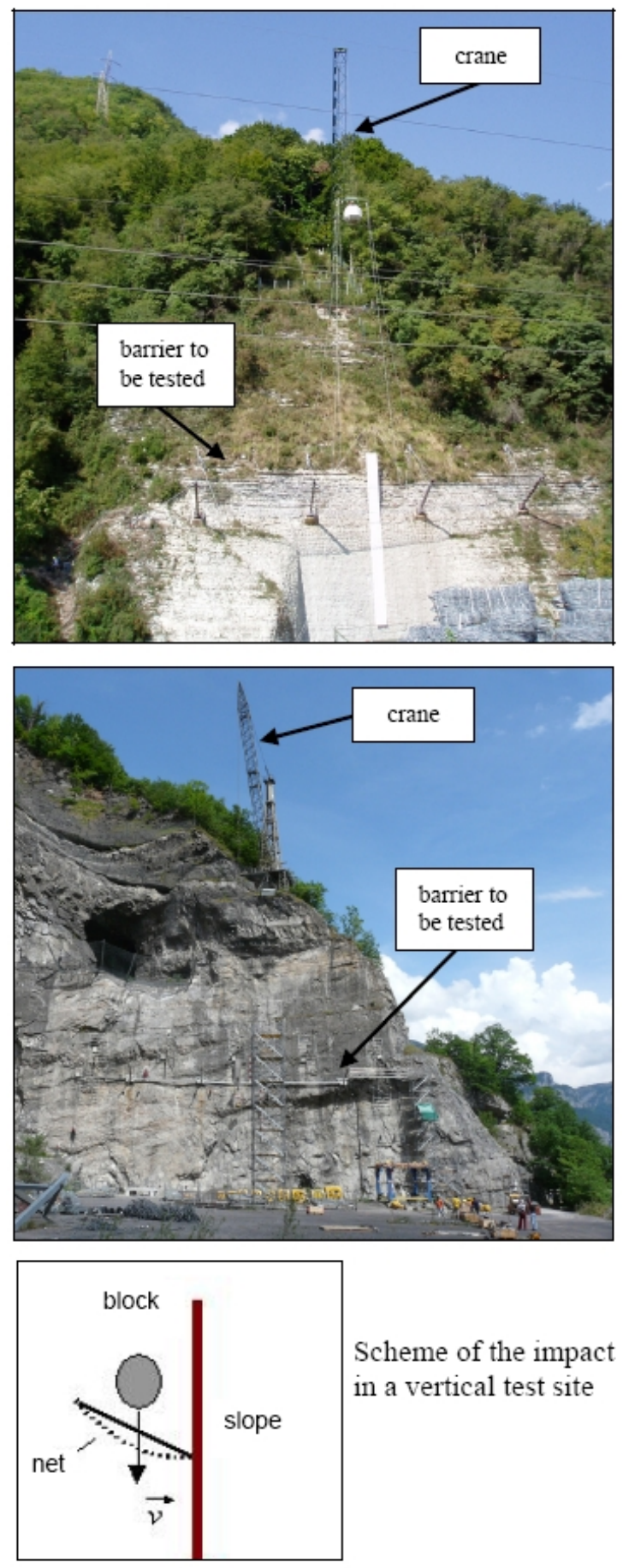

Fig. 2. Example of the vertical test sites: Forzaso (BL), Italy (left), and Walenstadt, Switzerland (right).

The maximum deformation of the structure and the forces on the foundations are measured during the MEL test and reported in the ETA document.

The development of the ETA document not only requires the previously described full-scale tests, but also a complete
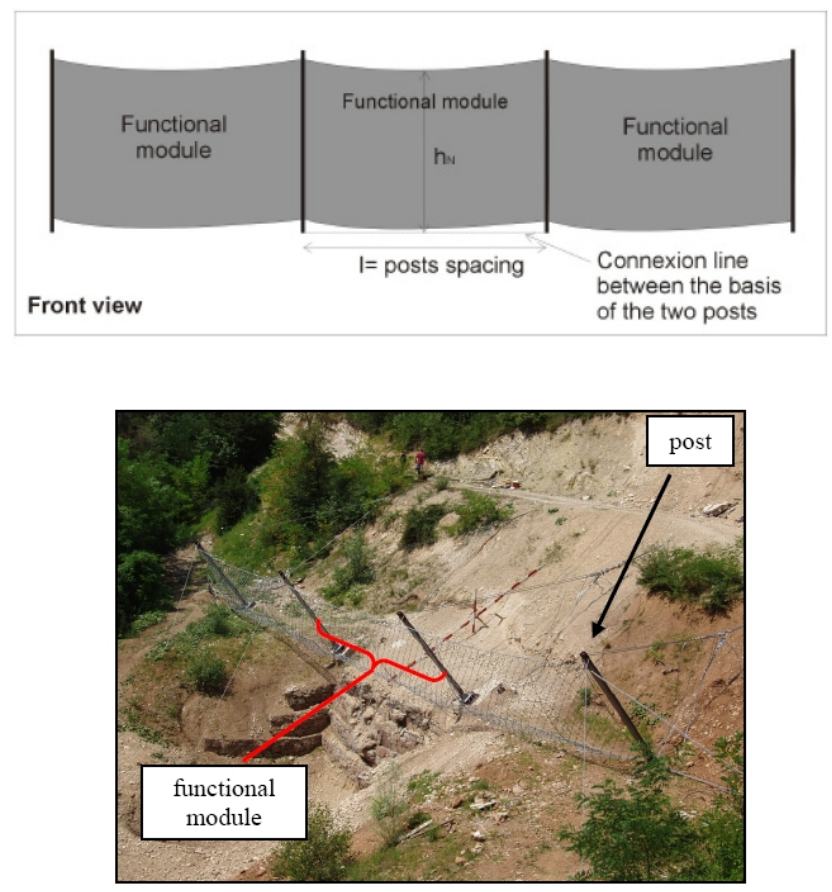

Fig. 3. Front view and picture of the falling rock protection kit with the definition of the most important geometrical properties.

evaluation of the factory production control and an analysis of the accompanying documents (i.e. installation manual, maintenance and handling procedures).

The Approved Bodies have to check that the factory production control, which has been activated by the manufacturer and the ETA-holder, maintains continuous surveillance and that a traceable documentation of all the production processes is available.

The standard conditions for the installation of falling rock protection kits in real sites should be clearly described in the manufacturer's installation guide, where the producer, on his own discretion, should provide the technical specifications of all the components and the admissible geometric tolerances, particularly concerning the spacing of the posts and the dip of the main ropes. It is very important to highlight that the height of the barrier cannot be reduced, with reference to the tested kit, and cannot be raised by more than $1 \mathrm{~m}$ for a tested height of no less than $4 \mathrm{~m}$ and $0.5 \mathrm{~m}$ for a tested height of lower than $4 \mathrm{~m}$.

\section{Design procedure for rockfall restraining nets}

The design of protection devices in an area prone to rockfall is a complex task that requires the designer to take into account many different kinds of data from the site (i.e. geological, geotechnical and topographical) and from the trajectory forecast, as summarized in Fig. 8. When the best position of the protection devices and the impact energy have been 


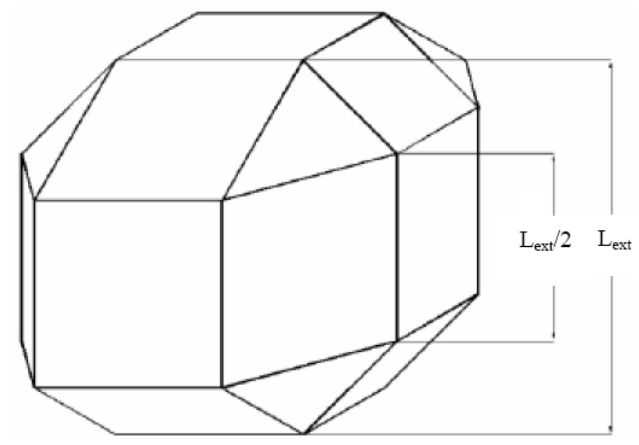

Fig. 4. Shape of the block (as foreseen in ETAG 027).

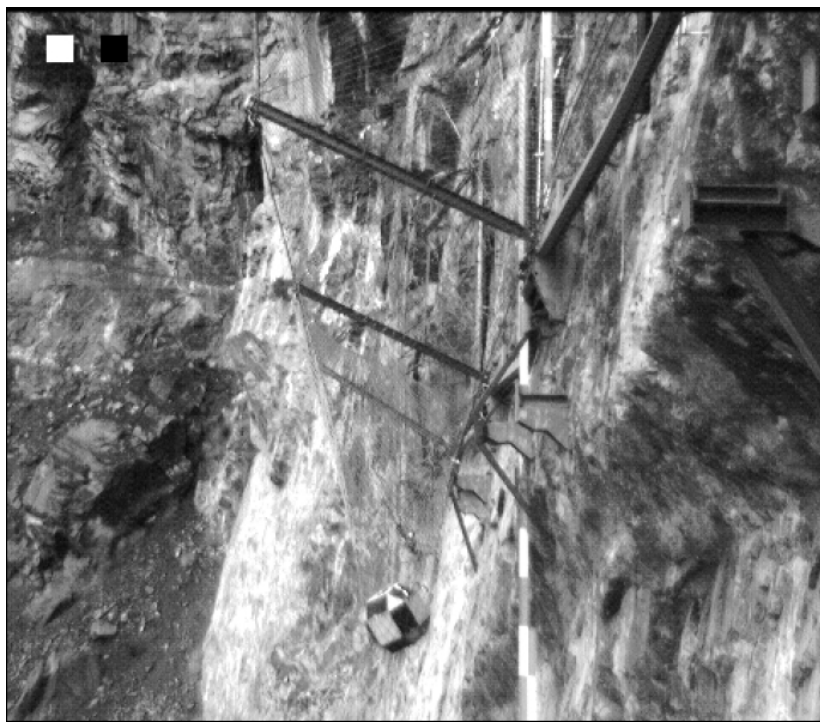

Fig. 5. Photogram of the video of a full-scale test in a vertical test site for a $500 \mathrm{~kJ}$ net fence when the maximum elongation is reached (courtesy SAFE s.r.l.).

evaluated, on the basis of the trajectory forecast, it is necessary to design and choose the correct net fence on the basis of the design laws in force (for example Eurocode 7 - EN 1997-1:2004).

The first design step is to choose whether to design using a MEL or SEL approach:

- in the case of a forecast of low frequency rockfall events and with different fall directions, in other words, not involving the same modulus, it is possible to adopt the MEL approach;

- if the barrier has to be installed in positions in which it is difficult to carry out maintenance work and it is therefore preferable not to repair it after each block impact, the SEL design approach should be chosen (considering that the design safety factor is three);

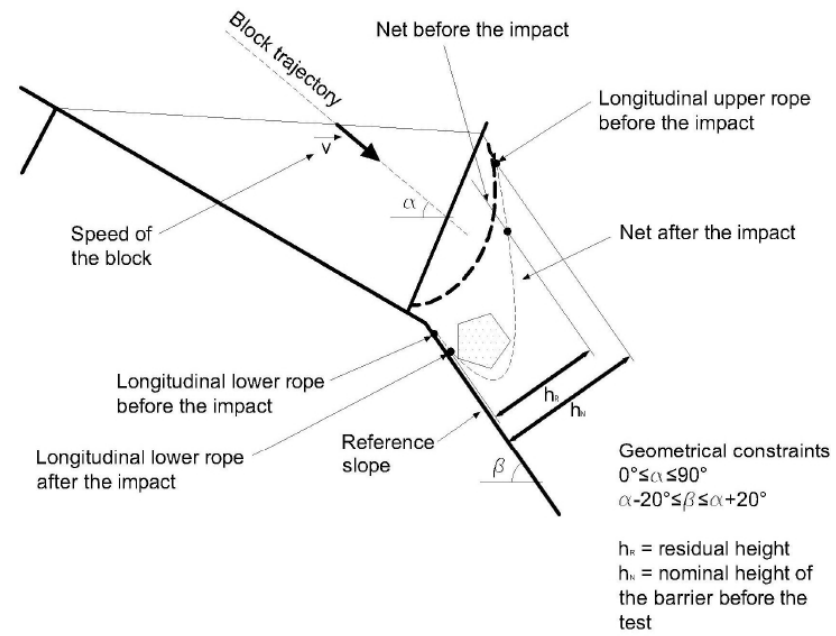

Section view of the test site

Fig. 6. Scheme of the test conditions and of the measurement of the barrier height as defined in ETAG 027.

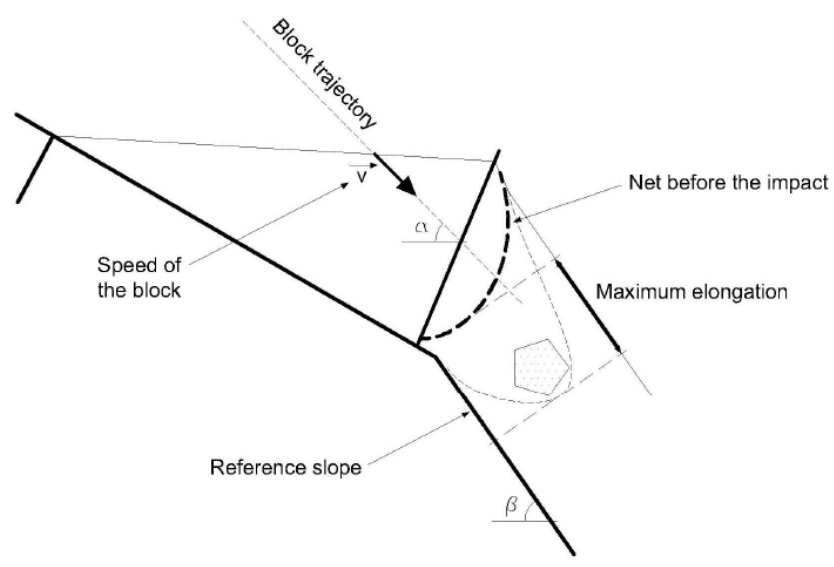

Fig. 7. Cross section of the kit with the definition of the maximum elongation as defined in ETAG 027.

- where the same modulus could be impacted several times, that is, in the same direction, the designer's choice could be: installation of two net fences with the alignment defined at a MEL level or one net fence with the alignment designed at a SEL level.

The designer should then verify that:

- the energy that can be dissipated by the net fences is greater than the computed energy of the block:

$E_{\text {design }}-\frac{E_{\text {ETA,netfences }}}{\gamma_{E}} \leq 0$

where: $\gamma_{E}$ is a safety factor, which is suggested as 1.30 , if the barrier is designed taking into account the MEL energy level (as used in Eurocode 7 in Design Approach 2), and 1.00 


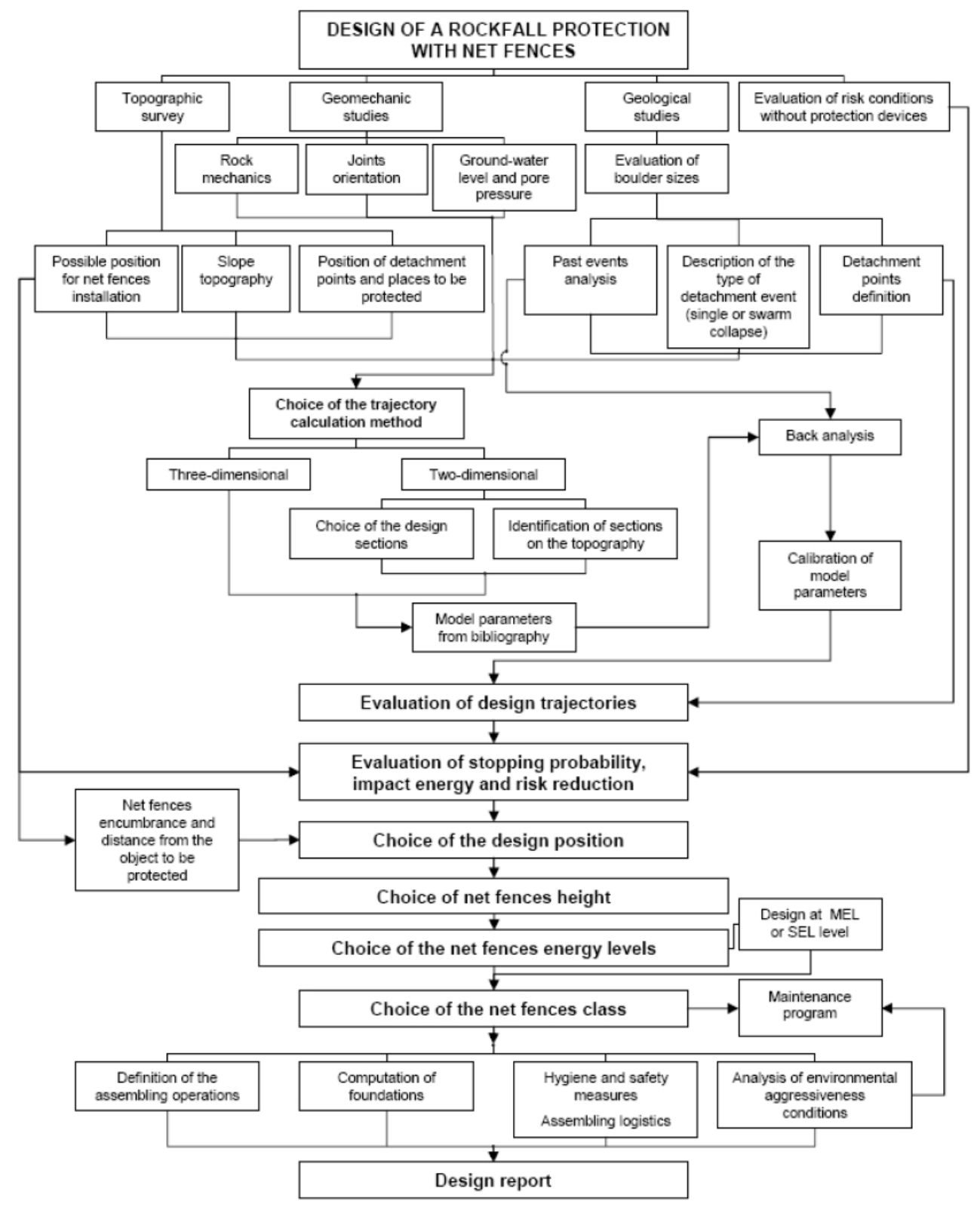

Fig. 8. Flow chart for the design of a rockfall protection device in an area prone to rockfall (modified from Peila et al., 2006).

if it is designed taking into account the SEL energy level (as used in Eurocode 7$) ; E_{\text {ETA,netfences }}$ is the energy certified by ETA (MEL or SEL);

- the interception height $\left(h_{i}\right)$ of the net fence is greater than the design interception height $\left(h_{p}\right)$, which is determined from the trajectory forecast, taking into account the computed block passage height relative to the slope (95\% percentile) in the design position plus a clearance $(f)$ that is not less than half the average size of the block:

$h_{i} \geq h_{p}+f$
- the maximum barrier elongation towards the valley $\left(d_{a}\right)$, multiplied by a safety factor $\left(\gamma_{E}\right)$, must be smaller than the design distance between the net fence alignment and the area that has to be protected $\left(d_{p}\right)$ :

$d_{a} \gamma_{E} \leq d_{p}$

This means that the barrier should always be installed at a sufficiently safe distance from the protected area.

The computation of the kinetic energy of the block during the impact is usually carried out using the computed block speed and the design block mass, applying the usual 
classical physics formulations and the concept of the partial safety factor, as indicated in Eurocode 7 (point 2.4.7.3.3).

The design speed of the block $\left(v_{p}\right)$ is obtained taking the calculated $95 \%$ percentile $\left(v_{t}\right)$ of the computed speeds of the falling trajectories as the characteristic value, multiplied by a safety factor $\left(\gamma_{F}\right)$ :

$v_{p}=v_{t} \gamma_{F}$

where $\gamma_{F}=\gamma_{T r} \gamma_{D p} \quad($ EN 1997-1:2004 Annex B; EN 1990:2002), with:

$\gamma_{T r}$, the reliability coefficient of the trajectory computation, which takes into account the possibility of deviation of the action values from their characteristic values, for which the following values are suggested:

$=1.00$ in the case of statistical computations derived from a back analysis;

$=1.10$ in the case of computations based on restitution coefficients obtained from bibliographic information;

$\gamma_{D p}$, the partial factor linked to the slope discretization quality that takes into account the uncertainties involved in modelling the actions, for which the following values are suggested:

$=1.05$ for a carefully discretized slope characterized by a precise topographic survey;

$=1.10$ for a slope modelled with a simplified 2-D crosssection derived from a large scale map.

These partial factors should be considered as suggestions and must be defined and evaluated from case to case for each problem.

The design block mass $\left(m_{p}\right)$ is equal to the product of the design block volume $\left(\mathrm{Vol}_{b}\right)$ and the rock unit weight $(\gamma)$ multiplied by a specific safety factor $\left(\gamma_{m}\right)$ :

$m_{p}=\left(\operatorname{Vol}_{b} \gamma\right) \gamma_{m}$

where $\gamma_{m}=\gamma_{\text {VolF1 }} \gamma_{y}$ (EN 1997-1: 2004 Annex B; EN 1990:2002), with: $\gamma_{y}$, the coefficient derived from the rock unit weight evaluation, which can be assumed equal to 1.00;

$\gamma_{\mathrm{VolF}}$, the coefficient derived from the volumetric survey accuracy of the "design block" which should be chosen on the basis of the "engineering judgement" of the designer, for which the following values are suggested:

$=1.05$ for a precise survey of the rock slope, for example obtained from a detailed reconstruction of the rock slope using laser scanning, photogrammetric methods or several direct geological surveys of the slope;

$=1.10$ for a survey of the rock slope carried out with only a limited number of site investigations.

\section{Conclusions}

The new ETAG 027 is playing an important role in the design of falling rock protection kits as it is a credited guideline to test these protection devices. For the first time, a testing standard (that is utilized in all UE Countries) makes it possible to compare products on the basis of their absorbable energy level.

Other significant information for designers, such as the maximum elongation of the net fences and the forces applied to the foundations, can be obtained during full scale tests and this will lead to an improvement in the design quality of a protection device, as shown by the proposed design procedure.

These data can be combined for a robust design which includes the systematic use of partial safety factors, such as prescribed by the geotechnical Eurocode design approach, which represents the official standard in force in Europe for geotechnical work design.

Acknowledgements. This study was financially supported by the National Research Project PRIN 2007, Application of advanced technologies to the safety, environmental protection, optimization of management and yield in quarries: geomining characterization and monitoring methodologies (National coordinator: Prof. Paolo Berry; Local coordinator of the DITAG Research unit, Politecnico di Torino: Daniele Peila).

Edited by: K. Schellenberg

Reviewed by: A. Roth and another anonymous referee

\section{References}

Agliardi, F. and Crosta, G. B.: High resolution three-dimensional numerical modelling of rockfalls, Int. J. Rock. Mech. Min., 40(2), 455-471, 2003.

Azzoni, A., La Barbera, G., and Zaninetti, A.: Analysis and prediction or rockfalls using a mathematical model, Int. J. Rock. Mech. Min., 32, 709-724, 1995.

Broili, L.: In situ tests for the study of rockfall, Geologia Applicata e Idrogeologia, 8, 105-111, 1973.

Bunce, C. M., Cruden, D. M., and Morgenstern, N. R.: Assessment of the hazard from rockfall on a highway, Can. Geotech. J., 34, 344-356, 1997.

Cazzani, A., Mongiovì, L., and Frenez, T.: Dynamic finite element analysis of interceptive devices for fallings rocks, Int. J. Rock. Mech. Min., 39(3), 303-321, 2002.

Construction Products Directive 89/106/EEC (CPD): Council Directive of 21 December 1988 on the approximation of laws, regulations and administrative provisions of the Member States relating to construction products, http://ec.europa.eu/, last access: 12/02/09, 1989.

Descoeudres, F. and Zimmermann, T.: Three-dimensional dynamic calculation of rockfalls, in: Proceedings of 6th International Congress on Rock Mechanics, Montreal, Canada, 30 August-3 September 1987, 337-342, 1987. 
Duffy, J. D. and Wade, H. : Field Tests and Evaluation of HI-Tech 50 and 70 Foot-ton Rockfall Fence, Report No. CA/05-96-02, CALTRANS, 1996.

EN 1990: Eurocode - Basis of structural design, 2002.

EN 1997-1: Eurocode - Geotechnical design - Part 1: General rules, 168 pp., 2004.

European Organization for Technical Approval (EOTA):: http:// www.eota.eu, last access 16/06/09, 2009.

ETAG 027: Guideline for European Technical Approval of Falling Rock Protection Kits, http://www.eota.eu/, last access: 16/06/09, 53 pp., 2008.

Gerber, W.: Highly flexible wire net rock fall barriers, in: Proceedings of the Joint Japan-Swiss Scientific Seminar on Impact Loads by Rock Falls and Design of Protection Structures, Kanazawa, Japan, 4-7 October 1999, 37-42, 1999.

Gerber, W.: Guideline for the approval of rockfall protection kits, Swiss Agency for the Environment, Forests and Landscape (SAEFL) and the Swiss Federal Research Institute WSL Berne, Bern, Swiss, 2001.

Giani G. P.: Rock slopes stability analysis, Balkema, Rotterdam, Netherlands, 374 pp., 1992.

Grassl, H., Bartelt, P., Volkwein, A., and Wartmann, S.: Experimental and numerical modelling of highly flexible rockfall protection barriers, in: Proceedings of 12th Panamerican Conference on Soil Mechanics and Geotechnical Engineering, Cambridge, Massachusetts, USA, 22-26 June 2003, 2589-2594, 2003.

Grass, H., Volkwein, A., Anderheggen, E., and Ammann, W. J.: Steel-net rockfall protection - experimental and numerical simulation, in: Proceedings of Seventh International Conference on Structures Under Shock and Impact, Montreal, Canada, May 2002, 143-153, 2002.

Guideline for the approval of rockfall protection kits - Amendment 2006, www.environment-switzerland.ch/publications, last access 12/06/09, 2006.

Guzzetti, F., Reichenbach, P., and Wieczorek, G. F.: Rockfall hazard and risk assessment in the Yosemite Valley, California, USA, Nat. Hazards Earth Syst. Sci., 3, 491-503, 2003, http://www.nat-hazards-earth-syst-sci.net/3/491/2003/.
Jaboyedoff, M., Dudt, J. P., and Labiouse, V.: An attempt to refine rockfall hazard zoning based on the kinetic energy, frequency and fragmentation degree, Nat. Hazards Earth Syst. Sci., 5, 621-632, 2005 ,

http://www.nat-hazards-earth-syst-sci.net/5/621/2005/.

Locatelli, L.: Analisi del rischio di caduta massi lungo un tratto della Gardesana Occidentale, GEAM Geoingegneria Ambientale e Mineraria, XLII (1), 33-44, 2005.

Nando Information System (Europa), http://ec.europa.eu/ enterprise/newapproach/nando, last access: 02/03/09, 2009.

Nicot, F., Cambou, B., and Mazzoleni, G.: Design of rockfall restraining nets from a discrete element modelling, Rock. Mech. Rock. Eng., 34(2), 98-118, 2001.

Peckover, F. L. and Kerr, W. G.: Treatment and maintenance of rock slopes on transportation routes, Can. Geotech. J., 14(4), 487507, 1977.

Peila, D. and Guardini, C.: Use of the event tree to assess the risk reduction obtained from rockfall protection devices, Nat. Hazards Earth Syst. Sci., 8, 1441-1450, 2008, http://www.nat-hazards-earth-syst-sci.net/8/1441/2008/.

Peila, D., Oggeri, C., and Baratono, P.: Barriere paramassi a rete: interventi e dimensionamento. GEAM Associazione Georisorse e Ambiente ed., Torino, Italy, 127 pp., 2006.

Peila, D., Oggeri, C., and Castiglia, C.: Ground reinforced embankments for rockfall protection: design and evaluation of full scale tests, Landslides, 4, 255-265, 2007.

Smith, D. D. and Duffy, J. D.: Field tests and evaluation of rockfall restraining nets, No. CA/TL-90/05, Final Report, CALTRAN, 1990.

Valfrè, A.: Dimensionamento di reti metalliche in aderenza per scarpate rocciose mediante modellazioni numeriche, GEAM Geoingegneria Ambientale e Mineraria, 4, 47-54, 2006.

Volkwein, A.: Numerical simulation of flexible rockfall protection system, in: Proceedings of congress on Computing in civil engineering, Cancun, Mexico, 12-16 July 2005, 2005.

Yang, M., Fukawa, T., Ohnishi, Y., Nishiyama, S., Miki, S., Hirakawa, Y., and Mori, S.: The application of 3-dimensional DDA with a spherical rigid block for rockfall simulation, Int. J. Rock. Mech. Min., 41(3), p. 476, 2004. 